\title{
Risk Perception and Foreign Exchange Risk Management in Microfinance
}

\author{
Christopher Priberny ${ }^{1} \&$ Gregor Dorfleitner ${ }^{1,2}$ \\ ${ }^{1}$ Department of Finance, University of Regensburg, Regensburg, Germany \\ ${ }^{2}$ CERMi (Centre for European Research in Microfinance), Belgium \\ Correspondence: Christopher Priberny, Department of Finance, University of Regensburg, 93040 Regensburg, \\ Germany. Tel: 49-941-943-5670. E-mail: christopher.priberny@ur.de
}

\author{
Received: September 27, 2012 Accepted: October 26, $2012 \quad$ Online Published: February 26, 2013 \\ doi:10.5539/jms.v3n2p68 URL: http://dx.doi.org/10.5539/jms.v3n2p68
}

\begin{abstract}
We study the perception of risks in the funding of microfinance institutions. A survey addressed to microfinance institutions and their funding organizations reveals that several risk types, among them foreign exchange (FX) risk, are not considered to be as important as reported in the relevant literature. We obtain further insights into the FX risk management of microfinance actors and reveal that many FX risk mitigation strategies and hedging tools are rarely used in practice.
\end{abstract}

Keywords: sustainable finance, microfinance, FX risk, risk management, survey

\section{Introduction}

The microfinance sector was subject to rapid growth in the years 2006 to 2010. This development was mainly enabled by the sector's ongoing interaction with international capital markets, which made microfinance institutions (MFIs) more and more independent from donations. Many MFIs were transformed from subsidized organizations into more professional and profit-orientated financial institutions. According to Ledgerwood and White (2006), the refinancing possibilities on international capital markets, allowing MFIs to enlarge their lending capacity, are "widely viewed as the best way to achieve the outreach needed to substantially increase access to financial services for the world's hundreds of millions of low-income households". This development has been boosted by the establishment of several international microfinance investment funds (MFIFs) and other, often structured, investment vehicles specialized in funding MFIs (see Dorfleitner, Leidl \& Priberny, 2011, for an overview). The investment in MFIs in direct or indirect form via MFIFs provides benefits for sustainable investors. Microfinance investments are regarded to provide reasonably good diversification effects if combined with stocks and bonds (Krauss \& Walter, 2009). Furthermore, investors can participate from a social return (Tulchin, 2003), which comes additionally to their financial revenue. The relevance of such a social component is confirmed by the incorporation of a social dimension into portfolio theory (e.g. Dorfleitner, Leidl \& Reeder, 2012; Barracchini \& Addessi, 2012).

According to El-Zoghbi, Gähwiler and Lauer (2011), funders reported a total amount of USD 21.3 billion of cross-border debt and equity invested in MFIs in December 2009. This implies an increase of 17\% in 2009 despite the global financial crisis. However, refinancing with international debt titles instead of donations makes MFIs more vulnerable to various risk types that are already well known in commercial banking. Granting microloans to borrowers does not only result in credit risk, but also in liquidity risk due to the refinancing process, interest rate risk and foreign exchange $(\mathrm{FX})$ risk and furthermore to operational risks such as staff fraud (Churchill \& Frankiewicz, 2006).

In particular the issue of FX risk is regarded as a challenge for the microfinance industry, which has to be dealt with in order to achieve a stable and sustainable long-term MFI funding. MFIs and MFIFs that provide MFIs with loans in local currency are particularly supposed to naturally have a large FX risk exposure. According to Barrès (2007), FX risk occurs due to the mismatch of currencies in which assets and liabilities are denominated, combined with uncertainty about future FX fluctuations. Many MFIs operating in emerging markets face a mismatch between the currency of liabilities and assets, which concerns mainly loans granted to microborrowers. The financial markets in developing countries are, in many cases, not mature enough to provide sufficient funds 
for MFIs in local currencies. Swanson (2007) highlights several reasons for this phenomenon: The bond markets in most developing countries are poorly regulated and thin, local commercial banks often lack deeper knowledge on how to analyze the risk associated with microfinance and therefore shrink away from investing in MFIs and there may also be investment restrictions that exclude microfinance. Holden and Holden (2004) state that therefore the majority of MFIs is forced to refinance themselves, at least partially, by borrowing in hard currencies, mainly USD and EUR, while offering loans to clients in the local currency.

Featherston, Littlefield and Mwangi (2006) quote that many developing countries face reasonably high FX fluctuations, which is backed by the studies on exchange rates from Cavazos (2004) and Abrams (2008). Existing literature has so far clarified in which way the microfinance industry is affected by FX risk (Featherston et al., 2006; Abrams \& Schneider-Moretto, 2008) and which tools can be used to mitigate the FX risk exposure. Generally, these are swaps, cross currency swaps, futures, options, back-to-back loans, foreign currency deposits, countervailing deposits and currency devaluation accounts. Such instruments have already been discussed and explained in detail by Holden and Holden (2004), Cavazos (2004), Bhatia (2004) and Featherston et al. (2006).

However, for many currencies the instruments mentioned above are not available. For such cases a currency exchange fund such as the Dutch 'TCX fund' (see www.tcxfund.com) could be considered as an appropriate alternative. TCX holds long-term emerging market currency and interest rate derivatives amounting to a total volume of about USD 700 million in 2011 and manages its total FX risk through diversification. MFIs can also account for their FX exposure through mitigation techniques, such as limiting the funds received in foreign currencies or an indexation of microloans to a hard currency.

Relatively little insight exists about how microfinance actors assess different risk types, in particular FX risk, and FX risk management tools. To our best knowledge, Barrès (2007) is currently the only author who has published survey results on FX risk management of MFIFs. By conducting a survey on risk types and FX management strategies in the MFI funding process addressed to a comprehensive group of microfinance actors we try to fill the existing gap. In Section 2 we present the survey methodology, design and samples. In Section 3 we discuss the results on selected issues with respect to the existing literature. Section 4 concludes the paper.

\section{Survey and Methodology}

From July 8th, 2010, to August 11th, 2010, we conducted a web-based survey asking approximately 900 organizations involved in microfinance how they assess several risk types, in particular FX risk, and risk management tools. The addressees of the survey were affiliated to MFIs and MFI funders, which we summarize as MFIFs. Furthermore, we accepted answers by experts consulting such organizations. We used a standardized online questionnaire to facilitate anonymity. A sum of 198 persons participated but some of them did not complete the questionnaire and were therefore excluded from the sample. This results in 164 observations, which correspond to a response rate of approximately $18 \%$. The survey design differentiates between MFIs and MFIFs, as we suspect differences regarding the risk perception of both groups. This discrimination allowed us to marginally adjust the questionnaire for MFIs or MFIFs. As a consequence we additionally asked MFIs about their total loan portfolio size, number of employees, average loan size and country of operation. The key figures characterizing the MFI sample are shown in Table 1.

Table 1. Key figures of the MFIs that participated in the survey shown as frequency tables

\begin{tabular}{lllllllll}
\hline Panel A & DEV & Africa & LAC & SEE & ME & CA & SEAP & Other \\
c.s. & & $3(3.53)$ & $10(11.76)$ & $27(31.76)$ & $16(18.82)$ & $4(4.71)$ & $10(11.76)$ & $9(10.59)$ \\
e.FX & & $1(2.17)$ & $6(13.04)$ & $16(34.78)$ & $6(13.04)$ & $3(6.52)$ & $4(8.70)$ & $4(8.70)$ \\
\hline Panel B & $<0.5$ & $0.50-2.50$ & $2.51-5.00$ & $5.01-7.50$ & $7.51-10.00$ & $10.01-50.00$ & $>50$ \\
c.s. & $2(2.35)$ & $12(14.12)$ & $8(9.41)$ & $8(9.41)$ & $3(3.53)$ & $39(45.88)$ & $13(15.29)$ \\
e.FX & $1(2.13)$ & $5(10.64)$ & $4(8.51)$ & $6(12.77)$ & $1(2.13)$ & $22(46.81)$ & $8(17.02)$ \\
\hline Panel C & $1-10$ & $11-50$ & $51-100$ & $101-500$ & $>500$ & & \\
c.s. & $2(2.41)$ & $11(13.25)$ & $20(24.10)$ & $31(37.35)$ & $19(22.89)$ & & \\
e.FX & $1(2.13)$ & $7(14.89)$ & $11(23.40)$ & $17(36.17)$ & $11(23.40)$ & & \\
\hline Panel D & $<100$ & $100-500$ & $501-1000$ & $1001-1500$ & $1501-2000$ & $2001-2500$ & $>2500$ \\
c.s. & $3(3.75)$ & $20(25.00)$ & $16(20.00)$ & $18(22.50)$ & $7(8.75)$ & $3(3.75)$ & $13(16.25)$ \\
e.FX & $2(4.26)$ & $10(21.28)$ & $10(21.28)$ & $13(27.66)$ & $4(8.51)$ & $3(6.38)$ & $5(10.64)$ \\
\hline
\end{tabular}

Description: 'c.s.' refers to the complete sample and 'e.FX' shows the results for a subsample consisting out of MFIs that are exposed to FX risk. Relative percentage values appear in parentheses. Panel A: Region, in which the MFI mainly operates. We distinguish between developed economies (DEV), Africa, Latin America and the Caribbean (LAC), Southern/Eastern Europe (SEE), Middle East (ME), Central Asia (CA), Southeast Asia and the Pacific (SEAP) and other. Panel B: Categorized size of MFI's total loan portfolio in mio. USD. Panel C: Categorized number of MFI's employees. Panel D: Average loan size of microloans in USD. 
The additional information allowed us to form suitable subsamples for a deeper investigation. First, small MFIs are suspected of lacking deeper knowledge on risk management. Therefore one might expect differences regarding the perception of risks and the risk management between small and large, established MFIs. To analyze this point we split the complete MFI sample, consisting of 95 answers, into two subsamples. Subsample 'large' consists of 52 MFIs with a total loan portfolio size larger than 10 mio. USD and a subsample 'small' with less than (or equal) 10 mio. USD including 32 observations. For eleven MFIs the loan portfolio size was not determinable. Second, a detailed analysis of the entire MFI sample reveals that some MFIs are not exposed to FX risk. As these might distort our results we create a subsample 'e.FX' of those 47 MFIs that are exposed to FX risk because a certain portion of their liabilities is denominated in a foreign currency and the local currency is not tied to the foreign currency. A corresponding subsample was created analogously for the MFIF sample, but in this case related to assets in local currency, which is a foreign currency from the MFIF's viewpoint.

It could be suspected that predominantly smaller, non-developed MFIs participated in the survey, which might distort the results due to selection bias. We clarify this issue by comparing the total loan portfolio size of the participating MFIs with comprehensive data on this measure obtained from an online platform operated by the Microfinance Information Exchange (see www.mixmarket.org) that comprises 1310 MFIs. Based on data from 2009, we test for differences regarding the distributions of the datasets by applying the one-sided Mann-Whitney U test (Mann \& Whitney, 1947). Our results show that our sample consists mainly of larger MFIs, in which financial risk management tools are assumed to be more common than in the under-represented smaller ones.

The results are presented in form of frequency tables in Section 3. The different levels of categorized data follow a numeric rating scale. In addition to the purely descriptive view, we apply the Wilcoxon signed rank test to test for significance. Regarding the responding experts as a representative sample, the test allows us to draw conclusions about the entire microfinance investment scene. Whereas most questions concerned how often instruments are used or how significant the participants consider different risks, we test with one-sided tests applied to both directions (e.g. neutral value versus rare and neutral value versus often) with a significance level of $10 \%$. Furthermore, we test for differences between the subsamples regarding several questions by using the Mann-Whitney U test. Again, we test in both directions with a confidence level of $10 \%$.

\section{Selected Issues and Discussion}

\subsection{Which Risk Types Are Considered as Being Significant by Microfinance Actors?}

The results of the survey regarding this question are shown in Table 2 for MFIs and in Table 3 for MFIFs. Our findings concerning the complete MFI sample indicate that MFIs do not consider fluctuations of donations to be crucial for their refinancing. Likewise, they rate risks concerning political stability and surprisingly FX risk as rather unimportant. Especially the last finding appears in deep contrast to the prevailing opinion that microfinance actors are expected to have a large FX risk exposure. However, the results might be distorted by some MFIs that are indeed not exposed to FX risk. With regard to FX risk, the data of the subsample 'e.FX' show a clear shift of the distribution towards importance, even if this cannot be proven by the Wilcoxon signed rank test. The same situation is observable for large MFIs. The only risk type regarded as being significant by MFIs is the one implied by macroeconomic factors, e.g. unemployment, inflation. Furthermore, we test for differences regarding the judgment of small MFIs and large MFIs considering the different risk types by using the Mann-Whitney U test. However, the tests do not reveal any significant differences in the risk assessment.

The results regarding the MFIF sample, shown in Table 3, contrast to those of the MFIs. Even though MFIs and MFIFs come to the same opinion regarding the dependency on donations and macroeconomic factors, MFIFs also consider credit risk and political stability to be significantly important. As is the case with MFI, for FX risk we observe a shift of the distribution towards importance in the subsample 'e.FX'. However, the Mann-Whitney $\mathrm{U}$ tests regarding differences in the risk assessment between MFIs and MFIFs indicate that MFIs only consider liquidity risk to be more severe than MFIFs do. 
Table 2. Risk assessment of MFIs

\begin{tabular}{|c|c|c|c|c|c|c|c|}
\hline & & 1 & 2 & 3 & 4 & 5 & Wilcoxon test \\
\hline \multirow[t]{4}{*}{ Dependency on donations } & c.s. & $30(50.00)$ & $8(13.33)$ & $13(21.67)$ & $3(5.00)$ & $6(10.00)$ & insign. $(<0.0001)$ \\
\hline & e.FX & $18(50.00)$ & $7(19.44)$ & $8(22.22)$ & $1(2.78)$ & $2(5.56)$ & insign. $(<0.0001)$ \\
\hline & large & $19(55.88)$ & $3(8.82)$ & $7(20.59)$ & & $5(14.71)$ & insign. (0.0016) \\
\hline & small & $11(42.31)$ & $5(19.23)$ & $6(23.08)$ & $3(11.54)$ & $1(3.85)$ & insign. (0.0018) \\
\hline \multirow[t]{4}{*}{ Operational risks } & c.s. & $6(8.33)$ & $16(22.22)$ & $28(38.89)$ & $10(13.89)$ & $12(16.67)$ & \\
\hline & e.FX & $3(6.82)$ & $8(18.18)$ & $20(45.45)$ & $6(13.64)$ & $7(15.91)$ & \\
\hline & large & $3(6.82)$ & $9(20.45)$ & $19(43.18)$ & $7(15.91)$ & $6(13.64)$ & \\
\hline & small & $3(10.71)$ & $7(25.00)$ & $9(32.14)$ & $3(10.71)$ & $6(21.43)$ & \\
\hline \multirow[t]{4}{*}{ Counterparty risk } & c.s. & $9(13.04)$ & $13(18.84)$ & $26(37.68)$ & $6(8.70)$ & $15(21.74)$ & \\
\hline & e.FX & $4(9.30)$ & $8(18.6)$ & $18(41.86)$ & $2(4.65)$ & $11(25.58)$ & \\
\hline & large & $7(16.28)$ & $6(13.95)$ & $15(34.88)$ & $6(13.95)$ & $9(20.93)$ & \\
\hline & small & $2(7.69)$ & $7(26.92)$ & $11(42.31)$ & & $6(23.08)$ & \\
\hline \multirow[t]{4}{*}{ Liquidity risk } & c.s. & $9(13.04)$ & $13(18.84)$ & $26(37.68)$ & $6(8.70)$ & $15(21.74)$ & \\
\hline & e.FX & $4(9.09)$ & $11(25.00)$ & $14(31.82)$ & $6(13.64)$ & $9(20.45)$ & \\
\hline & large & $6(13.95)$ & $7(16.28)$ & $14(32.56)$ & $6(13.95)$ & $10(23.26)$ & \\
\hline & small & $1(3.57)$ & $8(28.57)$ & $11(39.29)$ & $3(10.71)$ & $5(17.86)$ & \\
\hline \multirow[t]{4}{*}{ FX risk } & c.s. & $12(19.67)$ & $16(26.23)$ & $16(26.23)$ & $9(14.75)$ & $8(13.11)$ & insign. (0.0881) \\
\hline & e.FX & $3(7.14)$ & $10(23.81)$ & $15(35.71)$ & $9(21.43)$ & $5(11.90)$ & \\
\hline & large & $7(17.95)$ & $9(23.08)$ & $11(28.21)$ & $6(15.38)$ & $6(15.38)$ & \\
\hline & small & $5(22.73)$ & $7(31.82)$ & $5(22.73)$ & $3(13.64)$ & $2(9.09)$ & insign. (0.0618) \\
\hline \multirow[t]{4}{*}{ Interest rate risk } & c.s. & $7(10.14)$ & $18(26.09)$ & $22(31.88)$ & $16(23.19)$ & $6(8.70)$ & \\
\hline & e.FX & $4(9.52)$ & $13(30.95)$ & $12(28.57)$ & $9(21.43)$ & $4(9.52)$ & \\
\hline & large & $5(11.63)$ & $11(25.58)$ & $14(32.56)$ & $11(25.58)$ & $2(4.65)$ & \\
\hline & small & $2(7.69)$ & $7(26.92)$ & $8(30.77)$ & $5(19.23)$ & $4(15.38)$ & \\
\hline \multirow[t]{4}{*}{ Political instability } & c.s. & $15(22.06)$ & $17(25.00)$ & $21(30.88)$ & $8(11.76)$ & $7(10.29)$ & insign. (0.0129) \\
\hline & e.FX & $9(20.93)$ & $9(20.93)$ & $13(30.23)$ & $5(11.63)$ & $7(16.28)$ & \\
\hline & large & $9(20.93)$ & $9(20.93)$ & $13(30.23)$ & $7(16.28)$ & $5(11.63)$ & \\
\hline & small & $6(24.00)$ & $8(32.00)$ & $8(32.00)$ & $1(4.00)$ & $2(8.00)$ & insign. (0.0160) \\
\hline \multirow[t]{4}{*}{ Macroeconomic factors } & c.s. & $4(5.63)$ & $14(19.72)$ & $22(30.99)$ & $20(28.17)$ & $11(15.49)$ & sign. (0.0191) \\
\hline & e.FX & $2(4.55)$ & $8(18.18)$ & $15(34.09)$ & $9(20.45)$ & $10(22.73)$ & sign. (0.0142) \\
\hline & large & $3(6.82)$ & $10(22.73)$ & $13(29.55)$ & $12(27.27)$ & $6(13.64)$ & \\
\hline & small & $1(3.70)$ & $4(14.81)$ & $9(33.33)$ & $8(29.63)$ & $5(18.52)$ & sign. $(0.0244)$ \\
\hline \multirow[t]{4}{*}{ Climatic risk factors } & c.s. & $11(15.28)$ & $20(27.78)$ & $15(20.83)$ & $13(18.06)$ & $13(18.06)$ & \\
\hline & e.FX & $7(15.91)$ & $13(29.55)$ & $7(15.91)$ & $7(15.91)$ & $10(22.73)$ & \\
\hline & large & $4(9.09)$ & $16(36.36)$ & $10(22.73)$ & $9(20.45)$ & $5(11.36)$ & \\
\hline & small & $7(25.00)$ & $4(14.29)$ & $5(17.86)$ & $4(14.29)$ & $8(28.57)$ & \\
\hline
\end{tabular}

Description: Survey question: "How would you rate the following potential types of risk for your organization?" Frequency tables with relative percentage values in parentheses. Category 1 (category 5) means that the risk type is regarded as insignificant (very significant). The last column shows the results of one-sided Wilcoxon signed rank tests with the neutral category 3 as null hypothesis, whenever the test rejects at a significance level of $10 \%$ (p-value in parentheses). No entry corresponds to a non-significant test result. 'sign.' or 'insign.' means that the risk types are regarded as rather 'significant' or 'insignificant'. For a description of 'c.s.' and 'e.FX' see Table 1. 'large' and 'small' symbolize the subsamples of smaller and larger MFIs with respect to portfolio size. 'Counterparty risk' refers to the credit risk arising from lending to micro-entrepreneurs, 'Macroeconomic factors' means e.g. inflation, unemployment. 'Climatic risk factors' are e.g. drought, flooding. The size of the entire sample is 95 and 47,33 and 52 for the subsamples 'e.FX', 'small' and 'large'. 
Table 3. Risk assessment of MFIFs

\begin{tabular}{|c|c|c|c|c|c|c|c|}
\hline & & 1 & 2 & 3 & 4 & 5 & Wilcoxon test \\
\hline \multirow[t]{2}{*}{ Dependence on donations } & c.s. & $18(60.00)$ & $3(10.00)$ & $5(16.67)$ & $3(10.00)$ & $1(3.33)$ & insign. $(<0.0001)$ \\
\hline & e.FX & $13(65.00)$ & $2(10.00)$ & $3(15.00)$ & $2(10.00)$ & & insign. (0.0002) \\
\hline \multirow[t]{2}{*}{ Operational risks } & c.s. & $3(7.50)$ & $11(27.5)$ & $12(30.00)$ & $12(30.00)$ & $2(5.00)$ & \\
\hline & e.FX & $2(6.67)$ & $6(20.00)$ & $11(36.67)$ & $10(33.33)$ & $1(3.33)$ & \\
\hline \multirow[t]{2}{*}{ Counterparty risk } & c.s. & $4(9.09)$ & $7(15.91)$ & $8(18.18)$ & $11(25)$ & $14(31.82)$ & sign. (0.0057) \\
\hline & e.FX & $1(3.33)$ & $3(10.00)$ & $6(20.00)$ & $7(23.33)$ & $13(43.33)$ & sign. $(0.0003)$ \\
\hline \multirow[t]{2}{*}{ Liquidity risk } & c.s. & $9(20.93)$ & $11(25.58)$ & $9(20.93)$ & $13(30.23)$ & $1(2.33)$ & insign. (0.0299) \\
\hline & e.FX & $3(10.00)$ & $10(33.33)$ & $8(26.67)$ & $9(30.00)$ & & \\
\hline \multirow[t]{2}{*}{ FX risk } & c.s. & $7(17.95)$ & $8(20.51)$ & $8(20.51)$ & $10(25.64)$ & $6(15.38)$ & \\
\hline & e.FX & $4(13.79)$ & $6(20.69)$ & $7(24.14)$ & $8(27.59)$ & $4(13.79)$ & \\
\hline \multirow[t]{2}{*}{ Interest rate risk } & c.s. & $5(12.20)$ & $10(24.39)$ & $14(34.15)$ & $10(24.39)$ & $2(4.88)$ & \\
\hline & e.FX & $3(10.71)$ & $6(21.43)$ & $12(42.86)$ & $6(21.43)$ & $1(3.57)$ & \\
\hline \multirow[t]{2}{*}{ Political instability } & c.s. & $5(11.63)$ & $2(4.65)$ & $10(23.26)$ & $15(34.88)$ & $11(25.58)$ & sign. $(0.0066)$ \\
\hline & e.FX & $1(3.33)$ & & $6(20.00)$ & $14(46.67)$ & $9(30.00)$ & sign. $(<0.0001)$ \\
\hline \multirow[t]{2}{*}{ Macroeconomic factors } & c.s. & $1(2.22)$ & $7(15.56)$ & $16(35.56)$ & $14(31.11)$ & $7(15.56)$ & sign. (0.0046) \\
\hline & e.FX & & $4(12.90)$ & $9(29.03)$ & $12(38.71)$ & $6(19.35)$ & sign. (0.0009) \\
\hline \multirow[t]{2}{*}{ Climatic risk factors } & c.s. & $5(11.36)$ & $13(29.55)$ & $15(34.09)$ & $10(22.73)$ & $1(2.27)$ & insign. (0.0520) \\
\hline & e.FX & $3(9.68)$ & $8(25.81)$ & $11(35.48)$ & $8(25.81)$ & $1(3.23)$ & \\
\hline \multirow[t]{2}{*}{ Competition } & c.s. & $5(11.90)$ & $9(21.43)$ & $14(33.33)$ & $9(21.43)$ & $5(11.90)$ & \\
\hline & e.FX & $3(10.00)$ & $5(16.67)$ & $12(40.00)$ & $7(23.33)$ & $3(10.00)$ & \\
\hline
\end{tabular}

Description: Survey question: "How would you rate the following potential types of risk for your organization?" Frequency tables with relative percentage values in parentheses. Category 1 (category 5) means that risk type is regarded as insignificant (very significant). The last column shows the results of one-sided Wilcoxon signed rank tests with the neutral category 3 as null hypothesis, whenever the test rejects at a significance level of $10 \%$ (p-value in parentheses). No entry corresponds to a non-significant test result. 'sign.' or 'insign.' means that the risk types are regarded as rather 'significant' or 'insignificant'. For a description of 'c.s.' and 'e.FX' see Table 1. 'Counterparty risk' refers to the credit risk arising from lending to MFIs. 'Political instability' could occur in the country in which the MFI operates. For a description of 'Macroeconomic factors' and 'Climatic risk factors' see Table 2. 'Competition' occurs between the MFIF and other investors funding microfinance. The size of the entire sample is 69 and 32 for the subsample 'e.FX'.

\subsection{What Can Be Stated about Lending Currencies?}

Table 4 shows in which currencies liabilities of MFIs are denominated, while Table 5 displays the currency structure for loans to MFIs granted by MFIFs. The large portion of MFIs that receive funds in local currencies is remarkable. In fact, for 24 MFIs, i.e. $38.71 \%$ of the sample, a share of $76 \%$ to $100 \%$ of the liabilities is denominated in the local currency. This result is surprising and in stark contrast to the literature. We explore this issue in further detail for those 50 MFIs of our sample, which reported their size of the loan portfolio and the country they mainly operate in. We hypothesize that there could be a positive link between the development status of a country's financial system and the portion of the local currency the MFI's funding corresponds to. The first notion is proxied by the size of domestic credit provided by the banking sector as percentage of GDP which we obtained via The World Bank (see data.worldbank.org). The results of an OLS regression based on the data of 2009, in which we control for size effects, indicate that the portion of the local currency in MFI funding is indeed larger in countries with a more sophisticated financial system.

On the other hand, only two (4.88\%) MFIFs report upon not having granted loans in local currencies. Despite the increasing meaning of local currency, the results show that hard currencies still play an important role, especially USD and EUR, whereas GBP and CHF appear to play a secondary role.

Table 4. Survey question: "In what currency does your organization receive funds (e.g. equity, loans,...) from investors?"

\begin{tabular}{llllll}
\hline & $0 \%$ & $01 \%-25 \%$ & $26 \%-50 \%$ & $51 \%-75 \%$ & $76 \%-100 \%$ \\
\hline EUR & $9(34.62)$ & $8(30.77)$ & $2(7.69)$ & $4(15.38)$ & $3(11.54)$ \\
USD & $5(10.20)$ & $9(18.37)$ & $7(14.29)$ & $12(24.49)$ & $16(32.65)$ \\
CHF & $9(90.00)$ & $1(10.00)$ & & & $1(10.00)$ \\
GBP & $9(90.00)$ & & & & $24(38.71)$ \\
LC & $2(3.23)$ & $17(27.42)$ & $12(19.35)$ & $7(11.29)$ & 24 \\
\hline
\end{tabular}

Description: Frequency tables with relative percentage values in parentheses. The following categories are distinguished between: EUR, USD, CHF, GBB and local currency (LC). The sample size is 95. 
Table 5. Survey question: "In what currency do you provide funds for MFIs?"

\begin{tabular}{llllll}
\hline & $0 \%$ & $01 \%-25 \%$ & $26 \%-50 \%$ & $51 \%-75 \%$ & $76 \%-100 \%$ \\
\hline EUR & $3(13.64)$ & $11(50.00)$ & $2(9.09)$ & $2(9.09)$ & $4(18.18)$ \\
USD & $1(3.45)$ & $9(31.03)$ & $4(13.79)$ & $7(24.14)$ & $8(27.59)$ \\
CHF & $13(100.00)$ & & & & \\
GBP & $15(100.00)$ & & & & \\
LC & $2(4.88)$ & $16(39.02)$ & $4(9.76)$ & $1(2.44)$ & $18(43.90)$ \\
\hline
\end{tabular}

Description: Question was addressed to MFIFs. Frequency tables with relative percentage values in parentheses. The following categories are distinguished between: EUR, USD, CHF, GBB and local currency (LC). The sample size is 69.

\subsection{Which Strategies and Instruments Are Used to Manage FX Risk?}

On the MFI level we differentiate between pure FX mitigation strategies, displayed in Table 6, and hedging instruments, shown in Table 8. The latter are based on international capital markets and implemented in cooperation with a financial intermediary. Generally, these instruments are also available for MFIFs. In contrast, mitigation strategies are measures employed to cope with FX risk on the MFI level, that also include relatively simple techniques such as setting limits to FX exposure or transferring the FX risk either to the microborrowers through indexation to hard currency or to the MFIFs by using currency devaluation accounts. Contrary to the prevailing opinion in the literature, all hedging instruments mentioned in the questionnaire are extremely rarely used except for back-to-back loans, which are employed by a few MFIs.

The Wilcoxon signed rank tests indicate that nearly all FX mitigation strategies (Table 6) and hedging tools (Table 8) are applied rather seldomly. However, when comparing the figures of both tables the last ones appear to be used still more frequently. A comparison of small versus large MFIs via the Mann-Whitney U test shows that small MFIs draw on the indexation of microloans to hard currency more often than large MFIs.

According to the results shown in Table 7, MFIFs use hedging instruments rather seldomly, with the exception of cross currency swaps. However, they appear to employ such instruments more often than MFIs, particularly cross currency swaps and futures. Unfortunately, this is not backed by the Mann-Whitney U tests, which only allow the conclusion that MFIs apply options more often than MFIFs. 
Table 6. Usage of FX mitigation strategies by MFIs

\begin{tabular}{|c|c|c|c|c|c|c|c|c|}
\hline & & 0 & 1 & 2 & 3 & 4 & 5 & Wilcoxon test \\
\hline \multirow[t]{4}{*}{ Limits } & c.s. & $6(13.04)$ & $12(26.09)$ & $3(6.52)$ & $7(15.22)$ & $6(13.04)$ & $12(26.09)$ & seld. $(0.0720)$ \\
\hline & e.FX & $4(11.76)$ & $9(26.47)$ & $3(8.82)$ & $7(20.59)$ & $4(11.76)$ & $7(20.59)$ & seld. (0.0570) \\
\hline & large & $5(15.62)$ & $7(21.88)$ & $2(6.25)$ & $3(9.38)$ & $5(15.62)$ & $10(31.25)$ & \\
\hline & small & $1(7.14)$ & $5(35.71)$ & $1(7.14)$ & $4(28.57)$ & $1(7.14)$ & $2(14.29)$ & seld. (0.0764) \\
\hline \multirow[t]{4}{*}{ Indexation to $\mathrm{HC}$} & c.s. & $21(44.68)$ & $12(25.53)$ & $5(10.64)$ & $5(10.64)$ & $1(2.13)$ & $3(6.38)$ & seld. $(<0.0001)$ \\
\hline & e.FX & $13(37.14)$ & $10(28.57)$ & $4(11.43)$ & $5(14.29)$ & $1(2.86)$ & $2(5.71)$ & seld. $(<0.0001)$ \\
\hline & large & $17(51.52)$ & $8(24.24)$ & $2(6.06)$ & $4(12.12)$ & & $2(6.06)$ & seld. $(<0.0001)$ \\
\hline & small & $4(28.57)$ & $4(28.57)$ & $3(21.43)$ & $1(7.14)$ & $1(7.14)$ & $1(7.14)$ & seld. $(0.0060)$ \\
\hline \multirow[t]{4}{*}{ Debt issuance in LC } & c.s. & $17(37.78)$ & $7(15.56)$ & $2(4.44)$ & $5(11.11)$ & $3(6.67)$ & $11(24.44)$ & seld. (0.0004) \\
\hline & e.FX & $14(42.42)$ & $4(12.12)$ & $2(6.06)$ & $3(9.09)$ & $3(9.09)$ & $7(21.21)$ & seld. (0.0011) \\
\hline & large & $12(37.5)$ & $6(18.75)$ & $1(3.12)$ & $3(9.38)$ & $2(6.25)$ & $8(25.00)$ & seld. (0.0022) \\
\hline & small & $5(38.46)$ & $1(7.69)$ & $1(7.69)$ & $2(15.38)$ & $1(7.69)$ & $3(23.08)$ & seld. $(0.0570)$ \\
\hline \multirow{4}{*}{$\begin{array}{l}\text { Refinancing with loans } \\
\text { from banks in LC }\end{array}$} & c.s. & $7(15.22)$ & $6(13.04)$ & $8(17.39)$ & $9(19.57)$ & $6(13.04)$ & $10(21.74)$ & \\
\hline & e.FX & $7(20.59)$ & $4(11.76)$ & $7(20.59)$ & $6(17.65)$ & $4(11.76)$ & $6(17.65)$ & seld. (0.0331) \\
\hline & large & $2(6.25)$ & $5(15.62)$ & $4(12.5)$ & $7(21.88)$ & $5(15.62)$ & $9(28.12)$ & \\
\hline & small & $5(35.71)$ & $1(7.14)$ & $4(28.57)$ & $2(14.29)$ & $1(7.14)$ & $1(7.14)$ & seld. (0.0104) \\
\hline \multirow{4}{*}{$\begin{array}{l}\text { Foreign currency } \\
\text { deposits, } \\
\text { Countervailing } \\
\text { FX deposits }\end{array}$} & c.s. & $14(31.11)$ & $10(22.22)$ & $9(20)$ & $4(8.89)$ & $1(2.22)$ & $7(15.56)$ & seld. $(<0.0001)$ \\
\hline & e.FX & $12(36.36)$ & $7(21.21)$ & $7(21.21)$ & $2(6.06)$ & $1(3.03)$ & $4(12.12)$ & seld. $(0.0001)$ \\
\hline & large & $8(25.81)$ & $5(16.13)$ & $7(22.58)$ & $4(12.9)$ & $1(3.23)$ & $6(19.35)$ & seld. (0.0074) \\
\hline & small & $6(42.86)$ & $5(35.71)$ & $2(14.29)$ & & & $1(7.14)$ & seld. (0.0015) \\
\hline \multirow{4}{*}{$\begin{array}{l}\text { Currency devaluation } \\
\text { accounts }\end{array}$} & c.s. & $23(52.27)$ & $10(22.73)$ & $5(11.36)$ & $2(4.55)$ & $2(4.55)$ & $2(4.55)$ & seld. $(<0.0001)$ \\
\hline & e.FX & $17(51.52)$ & $7(21.21)$ & $4(12.12)$ & $2(6.06)$ & $1(3.03)$ & $2(6.06)$ & seld. $(<0.0001)$ \\
\hline & large & $16(51.61)$ & $7(22.58)$ & $2(6.45)$ & $2(6.45)$ & $2(6.45)$ & $2(6.45)$ & seld. $(<0.0001)$ \\
\hline & small & $7(53.85)$ & $3(23.08)$ & $3(23.08)$ & & & & seld. (0.0007) \\
\hline
\end{tabular}

Description: Survey question: "Indicate what instruments or strategies other than hedging your organization uses to reduce your foreign exchange risk". Frequency tables with relative percentage values in parentheses. Category 1 (category 5) means that the strategy or instrument is rarely (often) used. Category 0 corresponds to no usage at all. The last column shows the results of one-sided Wilcoxon signed rank tests with the neutral category 3 (frequently used) as null hypothesis, whenever the test rejects at a significance level of $10 \%$ (p-value in parentheses). No entry corresponds to a non-significant test result. 'seld.' means that the strategy is used rather seldomly. For a description of 'c.s.', 'e.FX', 'large' and 'small' see Tables 1 and 2. 'Limits' refers to the limitation of funds received in hard currency (HC), 'indexation to HC' means that a devaluation of the local currency (LC) leads to higher interest payments on the microloans. The size of the entire sample corresponds to 95 and 47, 33 and 52 for the subsamples 'e.FX', 'small' and 'large'.

Table 7. Usage of FX hedging instruments by MFIFs

\begin{tabular}{lllllllll}
\hline & & 0 & 1 & 2 & 3 & 4 & 5 & Wilcoxon test \\
\hline FX trade desk & c.s. & $7(41.18)$ & $2(11.76)$ & & $1(5.88)$ & & $7(41.18)$ & seld. $(0.0416)$ \\
& e.FX & $6(42.86)$ & $2(14.29)$ & & $1(7.14)$ & $5(35.71)$ & seld. $(0.0361)$ \\
\hline OTC: currency swaps & c.s. & $10(66.67)$ & & & $1(6.67)$ & & $4(26.67)$ & seld. $(0.0029)$ \\
& e.FX & $9(69.23)$ & & & $1(7.69)$ & $3(23.08)$ & seld. $(0.0037)$ \\
\hline OTC: currency forwards & c.s. & $5(25.00)$ & $3(15.00)$ & $1(5.00)$ & $4(20.00)$ & $1(5.00)$ & $6(30.00)$ & \\
& e.FX & $5(26.32)$ & $3(15.79)$ & $1(5.26)$ & $4(21.05)$ & $1(5.26)$ & $5(26.32)$ & seld. $(0.0694)$ \\
\hline OTC: currency futures & c.s. & $14(87.50)$ & $2(12.50)$ & & & & & seld. $(<0.0001)$ \\
& e.FX & $13(86.67)$ & $2(13.33)$ & & & & & seld. $(0.0001)$ \\
\hline OTC: currency options & c.s. & $14(82.35)$ & $3(17.65)$ & & & & & seld. $(<0.0001)$ \\
& e.FX & $13(81.25)$ & $3(18.75)$ & & & & & seld. $(<0.0001)$ \\
\hline OTC: cross currency swaps & c.s. & $7(31.82)$ & & $1(4.55)$ & $2(9.09)$ & $3(13.64)$ & $9(40.91)$ & \\
\hline Back-to-back loans & e.FX & $6(30.00)$ & & $1(5.00)$ & $2(10.00)$ & $3(15.00)$ & $8(40.00)$ & \\
& c.s. & $7(41.18)$ & $3(17.65)$ & $3(17.65)$ & $3(17.65)$ & & $1(5.88)$ & seld. $(0.0015)$ \\
& e.FX & $6(37.5)$ & $3(18.75)$ & $3(18.75)$ & $3(18.75)$ & & $1(6.25)$ & seld. $(0.0025)$ \\
\hline
\end{tabular}

Description: Survey question: "When lending to MFIs in a currency other than a hard currency, indicate what instruments or strategies you use to hedge your loan portfolio against foreign exchange risk." Frequency tables with relative percentage values in parentheses. Category 1 (category 5) means that the strategy or instrument is rarely (often) used. Category 0 corresponds to no usage at all. The last column shows the results of one-sided Wilcoxon signed rank tests regarding neutral category 3 (frequently used) as null hypothesis, whenever the test rejects at a significance level of $10 \%$ (p-value in parentheses). No entry corresponds to a non-significant test result. 'seld.' means that the strategy is used rather seldomly. For a description of 'c.s.' and 'e.FX' see Table 1. 'FX trade desk' refers to the cooperation with an international bank. 'OTC' indicates that the instrument is traded 'over the counter'. The size of the entire sample is 69 and 32 for the subsample 'e.FX'. 
Table 8 . Usage of FX hedging instruments by MFIs

\begin{tabular}{|c|c|c|c|c|c|c|c|c|}
\hline & & 0 & 1 & 2 & 3 & 4 & 5 & Wilcoxon test \\
\hline \multirow[t]{4}{*}{ FX trade desk } & c.s. & $5(50.00)$ & $3(30.00)$ & $2(20.00)$ & & & & seld. $(0.0026)$ \\
\hline & e.FX & $4(50.00)$ & $2(25.00)$ & $2(25.00)$ & & & & seld. (0.0064) \\
\hline & large & $5(62.50)$ & $1(12.50)$ & $2(25.00)$ & & & & seld. (0.0059) \\
\hline & small & & $2(100.00)$ & & & & & \\
\hline \multirow[t]{4}{*}{ OTC: currency swaps } & c.s. & $6(60.00)$ & $2(20.00)$ & & $1(10.00)$ & & $1(10.00)$ & seld. $(0.0071)$ \\
\hline & e.FX & $5(62.50)$ & $1(12.50)$ & & $1(12.50)$ & & $1(12.50)$ & seld. $(0.0175)$ \\
\hline & large & $6(85.71)$ & & & & & $1(14.29)$ & seld. (0.0119) \\
\hline & small & & $2(66.67)$ & & $1(33.33)$ & & & \\
\hline \multirow[t]{4}{*}{ OTC: currency forwards } & c.s. & $4(40.00)$ & & $3(30.00)$ & $1(10.00)$ & $1(10.00)$ & $1(10.00)$ & seld. (0.0402) \\
\hline & e.FX & $3(37.50)$ & & $2(25.00)$ & $1(12.50)$ & $1(12.50)$ & $1(12.50)$ & seld. (0.0992) \\
\hline & large & $4(57.14)$ & & $1(14.29)$ & & $1(14.29)$ & $1(14.29)$ & seld. $(0.0603)$ \\
\hline & small & & & $2(66.67)$ & $1(33.33)$ & & & \\
\hline \multirow[t]{4}{*}{ OTC: currency futures } & c.s. & $7(77.78)$ & $1(11.11)$ & $1(11.11)$ & & & & seld. $(0.0030)$ \\
\hline & e.FX & $6(85.71)$ & $1(14.29)$ & & & & & seld. (0.0074) \\
\hline & large & $7(100.00)$ & & & & & & seld. (0.0054) \\
\hline & small & & $1(50.00)$ & $1(50.00)$ & & & & \\
\hline \multirow[t]{4}{*}{ OTC: currency options } & c.s. & $7(63.64)$ & $1(9.09)$ & & $2(18.18)$ & & $1(9.09)$ & seld. $(0.0052)$ \\
\hline & e.FX & $6(85.71)$ & $1(14.29)$ & & & & & seld. $(0.0074)$ \\
\hline & large & $7(77.78)$ & & & $1(11.11)$ & & $1(11.11)$ & seld. $(0.0064)$ \\
\hline & small & & $1(50.00)$ & & $1(50.00)$ & & & \\
\hline \multirow{4}{*}{$\begin{array}{l}\text { OTC: cross currency } \\
\text { swaps }\end{array}$} & c.s. & $5(55.56)$ & $2(22.22)$ & $2(22.22)$ & & & & seld. (0.0039) \\
\hline & e.FX & $4(57.14)$ & $2(28.57)$ & $1(14.29)$ & & & & seld. $(0.0010)$ \\
\hline & large & $5(71.43)$ & $1(14.29)$ & $1(14.29)$ & & & & seld. (0.0089) \\
\hline & small & & $1(50.00)$ & $1(50.00)$ & & & & \\
\hline \multirow[t]{4}{*}{ Back-to-back loans } & c.s. & $13(29.55)$ & $8(18.18)$ & $10(22.73)$ & $8(18.18)$ & $2(4.55)$ & $3(6.82)$ & seld. $(<0.0001)$ \\
\hline & e.FX & $8(25.00)$ & $5(15.62)$ & $7(21.88)$ & $7(21.88)$ & $2(6.25)$ & $3(9.38)$ & seld. (0.0012) \\
\hline & large & $8(25.00)$ & $6(18.75)$ & $7(21.88)$ & $6(18.75)$ & $2(6.25)$ & $3(9.38)$ & seld. (0.0008) \\
\hline & small & $5(41.67)$ & $2(16.67)$ & $3(25.00)$ & $2(16.67)$ & & & seld. $(0.0026)$ \\
\hline
\end{tabular}

Description: Survey question: "If there is hedging in place for at least a portion of the portfolio, which of the following hedging strategies does your organization use to reduce foreign exchange risk?" Frequency tables with relative percentage values in parentheses. Category 1 (category 5) means that the strategy or instrument is rarely (often) used. Category 0 corresponds to no usage at all. The last column shows the results of one-sided Wilcoxon signed rank tests with the neutral category 3 (frequently used) as null hypothesis, whenever the test rejects at a significance level of $10 \%$ (p-value in parentheses). No entry corresponds to a non-significant test result. 'seld.' means that the strategy is used rather seldomly. For a description of 'c.s.', 'e.FX', 'large' and 'small' see Tables 1 and 2. For a description of 'FX trade desk' and 'OTC' see Table 7. The size of the entire sample is 95 and 47, 33 and 52 for the subsamples 'e.FX', 'small' and 'large'.

\subsection{Why Does Some FX Risk Exposure Remain Unhedged?}

So far we have found evidence to prove that microfinance actors, particularly MFIs, are deterred from using the hedging instruments often described in the literature. The results presented in Table 9 indicate that MFIs and MFIFs do not use unmentioned alternatives either but rather leave parts of their FX exposure unhedged. In fact, none of the participating MFIs is hedged completely against FX risk. Even $65.71 \%$ of the MFIs belonging to the 'e.FX' sample do not hedge their FX exposure at all, whereas large MFIs tend to hedge a larger part. MFIFs manifest a slightly better hedging behavior, as $65 \%$ of the MFIFs exposed to FX risk hedge at least $21 \%$ of their FX exposure and only $18.75 \%$ abstain from hedging at least a part of their portfolio.

Possible reasons why MFIFs and MFIs neglect a portion of their FX risk are presented in Table 10 and Table 11, respectively. For MFIs, the high transaction costs are the only statistically significant reason. Note that MFIs are in fact well aware of FX risk, as shown by a share of $85.18 \%$ answering that 'no awareness of FX risk' is not the reason for the decision not to hedge. Similarly, the reasons 'bureaucracy', 'inefficiencies' and 'company policies' are also regarded as being insignificant. MFIs do not appear to be willing to accept FX risk for higher expected returns either. MFIFs regard the lack of adequate hedging tools to be the most important reason. Indeed, MFIFs generally seem to have relatively similar reasons for why they neglect FX risk. This is also confirmed by the fact that the Mann-Whitney $U$ tests show no significant differences regarding the perception of the various reasons. Neglecting FX risk in general seems to be caused by the lack of adequate hedging tools due to thin financial markets. 
Table 9. Share of FX exposure hedged by MFIs and MFIFs

\begin{tabular}{lllllll}
\hline & MFI (c.s.) & $\begin{array}{l}\text { MFI } \\
(\text { e.FX) }\end{array}$ & $\begin{array}{l}\text { MFI } \\
\text { (large) }\end{array}$ & $\begin{array}{l}\text { MFI } \\
\text { (small) }\end{array}$ & $\begin{array}{l}\text { MFIF } \\
\text { (c.s.) }\end{array}$ & $\begin{array}{l}\text { MFIF } \\
(\mathrm{e} . F X)\end{array}$ \\
\hline $0 \%$ & $32(66.67)$ & $23(65.71)$ & $21(63.64)$ & $10(71.43)$ & $14(31.11)$ & $6(18.75)$ \\
$1 \%-10 \%$ & & & & & $3(6.67)$ & $2(6.25)$ \\
$11 \%-20 \%$ & & & & & $5(11.11)$ & $4(12.5)$ \\
$21 \%-30 \%$ & $1(2.08)$ & $1(2.86)$ & $1(3.03)$ & & $17(37.78)$ & $14(43.75)$ \\
$31 \%-40 \%$ & $3(6.25)$ & $2(5.71)$ & $2(6.06)$ & $1(7.14)$ & $1(2.22)$ & $1(3.12)$ \\
$41 \%-50 \%$ & $6(12.5)$ & $5(14.29)$ & $5(15.15)$ & $1(7.14)$ & $1(2.22)$ & $1(3.12)$ \\
$51 \%-60 \%$ & & & & & $2(4.44)$ & $2(6.25)$ \\
$61 \%-70 \%$ & $3(6.25)$ & $1(2.86)$ & $2(6.06)$ & $1(7.14)$ & $1(2.22)$ & $1(3.12)$ \\
$71 \%-80 \%$ & & & & & & \\
$81 \%-90 \%$ & $3(6.25)$ & $3(8.57)$ & $2(6.06)$ & $1(7.14)$ & & $1(2.22)$ \\
$91 \%-99 \%$ & & & & & & $1(3.12)$ \\
$100 \%$ & & & & &
\end{tabular}

Description: Survey question MFIs: "If the funding currency of your loan portfolio differs from the operating currency, what percentage of funds received is hedged against foreign exchange rate fluctuations?" and survey question MFIFs: "Indicate what percentage of your organization's loan portfolio lent to MFIs in local currencies is hedged against foreign exchange rate fluctuations." Frequency tables with relative percentage values in parentheses. For a description of 'c.s.', 'e.FX', 'large' and 'small' see Tables 1 and 2 . The size of the entire sample is 95 for MFIs and 69 for MFIFs, 47 and 32 for the MFI and MFIF 'e.FX' subsamples, 33 and 52 for the subsamples 'small' and 'large'.

Table 10. Reasons why MFIFs neglect FX risk mitigation

\begin{tabular}{llllllll}
\hline & & 1 & 2 & 3 & 4 & 5 & Wilcoxon test \\
\hline No adequate tools & c.s. & $4(17.39)$ & $1(4.35)$ & $5(21.74)$ & $1(4.35)$ & $12(52.17)$ & sign. (0.0242) \\
& e.FX & $2(10.53)$ & $1(5.26)$ & $4(21.05)$ & $1(5.26)$ & $11(57.89)$ & sign. (0.0070) \\
\hline High transaction costs & c.s. & $5(21.74)$ & $3(13.04)$ & $6(26.09)$ & $3(13.04)$ & $6(26.09)$ & \\
& e.FX & $4(22.22)$ & $2(11.11)$ & $5(27.78)$ & $3(16.67)$ & $4(22.22)$ & \\
\hline Regulatory obstacles & c.s. & $7(35.00)$ & $4(20.00)$ & $6(30.00)$ & $1(5.00)$ & $2(10.00)$ & insign. (0.0296) \\
& e.FX & $5(31.25)$ & $4(25.00)$ & $5(31.25)$ & $1(6.25)$ & $1(6.25)$ & insign. (0.0274) \\
\hline Bureaucracy & c.s. & $10(52.63)$ & $7(36.84)$ & $1(5.26)$ & $1(5.26)$ & & insign. (0.0002) \\
& e.FX & $8(50.00)$ & $7(43.75)$ & $1(6.25)$ & & & insign. (0.0003) \\
\hline Inefficiencies & c.s. & $8(40.00)$ & $5(25.00)$ & $4(20.00)$ & $1(5.00)$ & $2(10.00)$ & insign. (0.0141) \\
& e.FX & $6(37.5)$ & $5(31.25)$ & $4(25.00)$ & & $1(6.25)$ & insign. (0.0086) \\
\hline Acceptance of higher risk & c.s. & $7(36.84)$ & $4(21.05)$ & $2(10.53)$ & $4(21.05)$ & $2(10.53)$ & insign. (0.0594) \\
& e.FX & $7(50.00)$ & $2(14.29)$ & $2(14.29)$ & $2(14.29)$ & $1(7.14)$ & insign. (0.0209) \\
\hline Company policies & c.s. & $8(50.00)$ & $2(12.50)$ & $1(6.25)$ & $3(18.75)$ & $2(12.50)$ & insign. (0.0408) \\
& e.FX & $6(46.15)$ & $1(7.69)$ & $1(7.69)$ & $3(23.08)$ & $2(15.38)$ & \\
\hline
\end{tabular}

Description: Survey question: "Which of the following issues do you consider a significant reason why part of your organization's loan portfolio might not be hedged against foreign exchange risk?" Frequency tables with relative percentage values in parentheses. Category 1 (category 5) means that the issue is regarded as being insignificant (very significant). The last column shows the results of one-sided Wilcoxon signed rank tests with the neutral category 3 (significant reason) as null hypothesis, whenever the test rejects at a significance level of $10 \%$ (p-value in parentheses). No entry corresponds to a non-significant test result. 'sign.' or 'insign.' means that the issues are regarded as rather 'significant' or 'insignificant'. For a description of 'c.s.', and 'e.FX' see Table 1. 'No adequate tools' could possibly be due to imperfections of financial markets in developing countries. 'High transaction costs' arise due to relatively small loan sizes. 'Regulatory obstacles' might prevent the installation of the required capacities (e.g. legal issues, money transfer limitations). 'Inefficiencies' are e.g. a large delay when setting up hedging facilities. The 'acceptance of higher risk' may be due to expected higher returns. 'Company policies' might allow a higher level of risk. The size of the whole sample is 69 and 32 for the subsample 'e.FX'. 
Table 11. Reasons why MFIs neglect FX risk mitigation

\begin{tabular}{|c|c|c|c|c|c|c|c|}
\hline & & 1 & 2 & 3 & 4 & 5 & Wilcoxon test \\
\hline \multirow[t]{4}{*}{ Not aware of FX risk } & c.s. & $12(44.44)$ & $11(40.74)$ & $3(11.11)$ & $1(3.70)$ & & insign. $(<0.0001)$ \\
\hline & e.FX & $8(42.11)$ & $7(36.84)$ & $3(15.79)$ & $1(5.26)$ & & insign. (0.0004) \\
\hline & large & $9(64.29)$ & $3(21.43)$ & $2(14.29)$ & & & insign. (0.0008) \\
\hline & small & $3(23.08)$ & $8(61.54)$ & $1(7.69)$ & $1(7.69)$ & & insign. (0.0029) \\
\hline \multirow[t]{4}{*}{ No adequate tools } & c.s. & $6(16.22)$ & $7(18.92)$ & $9(24.32)$ & $7(18.92)$ & $8(21.62)$ & \\
\hline & e.FX & $5(17.86)$ & $5(17.86)$ & $7(25)$ & $5(17.86)$ & $6(21.43)$ & \\
\hline & large & $5(25.00)$ & $1(5.00)$ & $5(25.00)$ & $3(15.00)$ & $6(30.00)$ & \\
\hline & small & $1(5.88)$ & $6(35.29)$ & $4(23.53)$ & $4(23.53)$ & $2(11.76)$ & \\
\hline \multirow[t]{4}{*}{ High transaction costs } & c.s. & $2(5.26)$ & $4(10.53)$ & $18(47.37)$ & $6(15.79)$ & $8(21.05)$ & sign. (0.0238) \\
\hline & e.FX & $1(3.45)$ & $2(6.9)$ & $16(55.17)$ & $5(17.24)$ & $5(17.24)$ & sign. $(0.0283)$ \\
\hline & large & $2(11.11)$ & $2(11.11)$ & $7(38.89)$ & $3(16.67)$ & $4(22.22)$ & \\
\hline & small & & $2(10.00)$ & $11(55.00)$ & $3(15.00)$ & $4(20.00)$ & sign. $(0.0257)$ \\
\hline \multirow[t]{4}{*}{ Regulatory obstacles } & c.s. & $9(27.27)$ & $7(21.21)$ & $9(27.27)$ & & $8(24.24)$ & \\
\hline & e.FX & $6(25.00)$ & $4(16.67)$ & $8(33.33)$ & & $6(25.00)$ & \\
\hline & large & $6(31.58)$ & $4(21.05)$ & $3(15.79)$ & & $6(31.58)$ & \\
\hline & small & $3(21.43)$ & $3(21.43)$ & $6(42.86)$ & & $2(14.29)$ & \\
\hline \multirow[t]{4}{*}{ Bureaucracy } & c.s. & $13(43.33)$ & $9(30.00)$ & $3(10.00)$ & & $5(16.67)$ & insign. (0.0081) \\
\hline & e.FX & $10(45.45)$ & $6(27.27)$ & $3(13.64)$ & & $3(13.64)$ & insign. (0.0099) \\
\hline & large & $9(56.25)$ & $4(25.00)$ & $1(6.25)$ & & $2(12.50)$ & insign. (0.0093) \\
\hline & small & $4(28.57)$ & $5(35.71)$ & $2(14.29)$ & & $3(21.43)$ & \\
\hline \multirow[t]{4}{*}{ Inefficiencies } & c.s. & $17(54.84)$ & $7(22.58)$ & $3(9.68)$ & $3(9.68)$ & $1(3.23)$ & insign. $(<0.0001)$ \\
\hline & e.FX & $13(59.09)$ & $3(13.64)$ & $3(13.64)$ & $2(9.09)$ & $1(4.55)$ & insign. (0.0007) \\
\hline & large & $11(73.33)$ & $3(20.00)$ & & & $1(6.67)$ & insign. (0.0013) \\
\hline & small & $6(37.50)$ & $4(25.00)$ & $3(18.75)$ & $3(18.75)$ & & insign. $(0.0088)$ \\
\hline \multirow[t]{4}{*}{ Acceptance of higher risk } & c.s. & $14(48.28)$ & $2(6.90)$ & $9(31.03)$ & $4(13.79)$ & & insign. (0.0002) \\
\hline & e.FX & $11(50.00)$ & $1(4.55)$ & $8(36.36)$ & $2(9.09)$ & & insign. (0.0007) \\
\hline & large & $10(66.67)$ & & $4(26.67)$ & $1(6.67)$ & & insign. (0.0011) \\
\hline & small & $4(28.57)$ & $2(14.29)$ & $5(35.71)$ & $3(21.43)$ & & insign. $(0.0568)$ \\
\hline \multirow[t]{4}{*}{ Company policies } & c.s. & $12(38.71)$ & $8(25.81)$ & $7(22.58)$ & $3(9.68)$ & $1(3.23)$ & insign. (0.0004) \\
\hline & e.FX & $8(33.33)$ & $7(29.17)$ & $7(29.17)$ & $2(8.33)$ & & insign. (0.0007) \\
\hline & large & $10(58.82)$ & $3(17.65)$ & $3(17.65)$ & $1(5.88)$ & & insign. (0.0006) \\
\hline & small & $2(14.29)$ & $5(35.71)$ & $4(28.57)$ & $2(14.29)$ & $1(7.14)$ & \\
\hline
\end{tabular}

Description: Survey question: "If a part of your foreign exchange risk exposure remains unhedged, indicate how significant the following issues are for this situation." Frequency tables with relative percentage values in parentheses. Category 1 (category 5) means that the issue is regarded as being insignificant (very significant). The last column shows the results of one-sided Wilcoxon signed rank tests with the neutral category 3 as null hypothesis, whenever the test rejects at a significance level of $10 \%$ (p-value in parentheses). No entry corresponds to a non-significant test result. 'sign.' or 'insign.' means that the issue is regarded as rather 'significant' or 'insignificant'. For a description of 'c.s.', 'e.FX', 'large' and 'small' see Tables 1 and 2. For a description of the possible reasons see Table 10. The size of the whole sample is 95 and 47, 33 and 52 for the subsamples 'e.FX', 'small' and 'large'.

\section{Conclusion}

We conclude that MFIs and MFIFs consider several risk types, among them FX risk, not to be as important as is commonly reported upon in the literature. Furthermore, we reveal that many FX risk management tools, recommended in the respective literature, are somewhat rarely used in practice. The reason for this phenomenon can be seen in the lack of suitable, cost effective hedging tools that remain unavailable for many MFIs and MFIFs. This paper contributes to closing the gap in existing literature on the question regarding how the microfinance sector assesses different risk types, especially FX risk.

\section{Acknowledgements}

We thank an anonymous referee for valuable comments and Daniel Uhlemann for data collection and extensive support. We are grateful to the participants of the 'Second European Research Conference on Microfinance', Groningen, for helpful comments. We thank the German Research Foundation (DFG), which provided financial support for the project 'Ökonomische Analyse der Refinanzierung von Mikrokreditvergabe'. Furthermore, this work was supported within the DGF funding programme 'Open Access Publishing'.

\section{References}

Abrams, J. (2008). Recent developments in microfinance foreign exchange risk management. Geneva Papers on Inclusiveness, 7. World Microfinance Forum Geneva. 
Abrams, J., \& Schneider-Moretto, L. (2008). From dollar to dinar: The rise of local currency lending and hedging in microfinance. Geneva Papers on Inclusiveness, 7. World Microfinance Forum Geneva.

Barracchini, C., \& Addessi, M. (2012). Ethical portfolio theory: A new course. Journal of Management and Sustainability, 2(2), 35-42. http://dx.doi.org/10.5539/jms.v2n2p35

Barrès, I. (2007). The Management of Foreign Exchange Risk by Microfinance Institutions and Microfinance Investment Funds. In Matthäus-Maier, I., \& Pischke, J. D. (Eds.), Microfinance Investment Funds: Leveraging Private Capital for Economic Growth and Poverty Reduction (pp. 115-146). Springer, Berlin, Heidelberg. http://dx.doi.org/10.1007/3-540-28071-5_8

Bhatia, R. (2004). Mitigating Currency Risk for Investing in Microfinance Institutions in Developing Countries. Social Enterprise Associates [Techreport].

Cavazos, R. (2004). Foreign Exchange Risk Management in Microfinance. Women's World Banking Occasional Paper, 1(2), 1-28.

Churchill, C., \& Frankiewicz, C. (2006). Making microfinance work: managing for improved performance. International Labour Office, Geneva.

Dorfleitner, G., Leidl, M., \& Priberny, C. (2011). Microcredit as an asset class: Structured microfinance. In Köhn, D. (Ed.), Mobilising Capital for Emerging Markets: What Can Structured Finance Contribute? (pp. 137-154). Springer, Berlin. http://dx.doi.org/10.1007/978-3-540-92225-4_12

Dorfleitner, G., Leidl, M., \& Reeder, J. (2012). Theory of social returns in portfolio choice with application to microfinance. Journal of Asset Management, 13(6), 384-400. http://dx.doi.org/10.1057/jam.2012.18

El-Zoghbi, M., Gähwiler, B., \& Lauer, K. (2011). Cross-border funding of microfinance. CGAP Focus Note, 70, CGAP.

Featherston, S., Littlefield, E., \& Mwangi, P. (2006). Foreign Exchange Rate Risk in Microfinance: What is it and how can it be managed? CGAP Focus Note, 31, 1-16. CGAP.

Holden, P., \& Holden, S. (2004). Foreign exchange risk and microfinance institutions: A discussion of the issues. MicroRate and the Economic Research Institute [Techreport].

Krauss, N. A., \& Walter, I. (2009). Can Microfinance Reduce Portfolio Volatility? Economic Development and Cultural Change, 58(1), 85-110. http://dx.doi.org/10.1086/605206

Ledgerwood, J., \& White, V. (2006). Transforming Microfinance Institutions. The World Bank - MicroFinance Network [Techreport].

Mann, H., \& Whitney, D. (1947). On a test of whether one of two random variables is stochastically larger than the other. The Annals of Mathematical Statistics, 18(1), 50-60. http:/dx.doi.org/10.1214/aoms/1177730491

Swanson, B. (2007). The Role of International Capital Markets in Microfinance. Developing World Markets [Techreport].

Tulchin, D. (2003). Microfinance's double bottom line: Measuring social return for the microfinance industry. Social Enterprise Associates [Techreport]. 